\title{
Analytical seismic assessment of RC dual wall/frame systems using SLaMA: proposal and validation
}

\author{
Roberto Gentile $^{\mathrm{a}^{*}}$, Stefano Pampanin ${ }^{\mathrm{b}, \mathrm{c}}$, Domenico Raffaele ${ }^{\mathrm{d}}$, Giuseppina Uva ${ }^{\mathrm{d}}$ \\ a) Institute for Risk and Disaster Reduction, University College London, London, United Kingdom \\ b) Department of Structural and Geotechnical Engineering, University of Rome "La Sapienza", Rome, \\ Italy
}

c) Department of Civil and Natural Resources Engineering, University of Canterbury, Christchurch, New Zealand

d) Department of Civil, Environmental and Landscape, Building Engineering and Chemistry, Polytechnic University of Bari, Bari, Italy

*corresponding author. Email: r.gentile@ucl.ac.uk

A paramount step in seismic assessment of existing structures is the determination of the structural capacity. It is widely recognised that non-linear numerical approaches are arguably the most reliable tool to achieve this goal. However, reliable yet simple analytical procedures are needed to identify potential structural weaknesses and their influence on the overall capacity, to cross-check and/or interpret numerical analyses. This paper presents a novel analytical -or "by-hand"- procedure to calculate the non-linear capacity curve of RC dual wall/frame systems within the framework of the Simple Lateral Mechanism Analysis (SLaMA). The mechanical interaction among frame(s) and wall(s) is explicitly considered to calculate their base shear and overturning moment contributions. The procedure is outlined and applied to 28 case studies with different geometry, wall-to-frame strength ratio and plastic mechanism. The results are compared to refined numerical pushover analyses, showing a maximum 5\% error both in terms of ultimate base shear and displacement for the majority of the case studies.

Keywords: seismic assessment; Displacement-Based Assessment DBA; Simple Lateral Mechanism Analysis SLaMA; non-linear analysis; reinforced concrete RC; dual wall/frame systems.

\section{Introduction}

The seismic behaviour of existing RC buildings can potentially be affected by a high number of structural 
"deficiencies" such as the lack of capacity design principles and inadequate reinforcement details, among others. For this reason, as part of a seismic assessment and definition of a retrofit strategy, there is the need of practical tools to check the reliability of non-linear numerical models -nowadays widespread, also in commercial software- to capture the probable plastic mechanism of a building.

Among other analytical non-linear procedures [Borzi et al., 2008, Crowley et al., 2004, Cardone and Flora, 2017], the Simple Lateral Mechanism Analysis (SLaMA) is a reliable yet efficient "by hand" procedure, implementable in a spreadsheet, that allows to explicitly calculate the actual hierarchy of strength between connecting members, predict the force-displacement capacity curve and the plastic mechanism of an RC building. The method originates from a pioneering capacity design-oriented procedure by [Priestley and Calvi, 1991], which is the basis for a displacement-based assessment procedure [Priestley, 1997], with many subsequent applications [Glaister and Pinho, 2003; Sullivan and Calvi, 2011; Calvi and Sullivan, 2013; Sullivan et al., 2014; Welch et al., 2014; Sullivan and Fox, 2015]. SLaMA was firstly introduced in the 2006 seismic assessment guidelines by the New Zealand Society for Earthquake Engineering [NZSEE 2006]. After significant effort in validating and refining the method [Del Vecchio et al., 2017, 2018, Gentile, 2017, Gentile et al., 2019a], SLaMA was included in the 2017 version of the New Zealand seismic assessment guidelines [NZSEE 2017]. Key original aspects when compared to the 2006 version and other procedure available in literature are a) the evaluation of the hierarchy of strength within a beam-column joint subassembly using a M-N interaction performance domain according to a procedure proposed by Pampanin et al. 2002; b) the evaluation of the global force-displacement curve based on the internal action following an equilibrium approach (Pampanin, 2015, personal communication and course notes) similar to what is proposed in the Displacement Based Design procedure (Priestley et al., 2007) but based on an inverted process.

Herein, a SLaMA procedure for RC bare frames (later extended to masonry-infilled frames by Gentile et al., 2019b,c) and walls is given. A tentative assessment procedure for RC dual wall/frame systems is provided in NZSEE 2017, already representing a refinement of the original NZSEE 2006 version. 
However, this approach does not yet explicitly consider the mechanical interaction between the wall(s) and the frame(s) in the dual system.

This paper presents a refined and novel SLaMA procedure for RC dual wall/frame structures that fills this gap and, given its generalised approach, is applicable to a wide range of configurations. The proposed assessment procedure for existing buildings, inspired by the displacement-based design method for (the design of new) RC dual systems proposed by Sullivan et al., [2006], is applied to a set of 28 case studies considering a wide range of configurations: 4 to 16 storeys, different wall-to frame strength ratios, one or more walls in different positions, presence or absence of link beams between walls and frames, symmetric vs asymmetric.

The SLaMA capacity curves are compared to the results of refined numerical pushover analyses, highlighting the reliability and effectiveness of the proposed procedure.

\section{The assessment procedure}

In RC dual wall/frame systems, walls are typically stiffer and stronger than the frame counterpart, and they might resist a significant portion of the total base shear. Due to displacement compatibility issues between the frame(s) and wall(s) parts, provided that the floor diaphragms are sufficiently strong and stiff, it is likely that the wall would control the drift profile of the dual system, potentially delaying or avoiding the development of a soft storey mechanism (Paulay and Goodsir, 1986; Lopes and Bento, 2001, NZSEE2017). In such conditions, the frame part is able to develop the full mechanism, thus attaining its strength capacity at each storey, regardless of the hierarchy of strength of the composing members (beam, columns, joints). The proposed SLaMA procedure is based on this hypothesis, which is subsequently confirmed for 28 case studies (Section 3), considering beam and column hinges and possible shear failure of joint panels.

The basic steps to determine the bi-linear capacity curve of an RC dual system according to the proposed SLaMA procedure are summarised in Figure 1. Those are discussed in detail in the following sections. 
- Step 1 - The lateral capacity for each structural member (beams, columns, joint panels, walls) is defined considering the most probable failure mechanisms:

- Step 2 - The hierarchy of strength is calculated for each beam-column joint sub-assembly.

- Step 3 - The shear strength of the frame part is calculated for each storey, together with the related portion of the inertia forces.

- Step 4 - Following an initial guess of the wall base shear, the portion of inertia forces acting on the wall and, in turn, the base shear capacity are calculated. Using the new value of the base shear, the process is iterated upon convergence (typically 2-3 iterations).

- Step 5 - With an assumption on the displacement shape of the system, the frame(s) and wall(s) capacity curves are calculated and summed to obtain the global capacity curve. The ultimate displacement is attained if the frame(s) or the wall(s) reach their ultimate displacement, whichever occurs first.

$V_{B, w}^{t r y}$ : trial value for wall yielding base shear; $V_{B y, w}, V_{B y, f}, V_{B y, t o t}:$ wall, frame and total base shear; $F_{w, i}, F_{f, i}, F_{t o t, i}:$ wall, frame and total force at storey i; $m_{i}:$ mass at storey i;

$H_{i}$ : height of storey i (from ground); N: column axial load; ECM: Equivalent Column Moment.

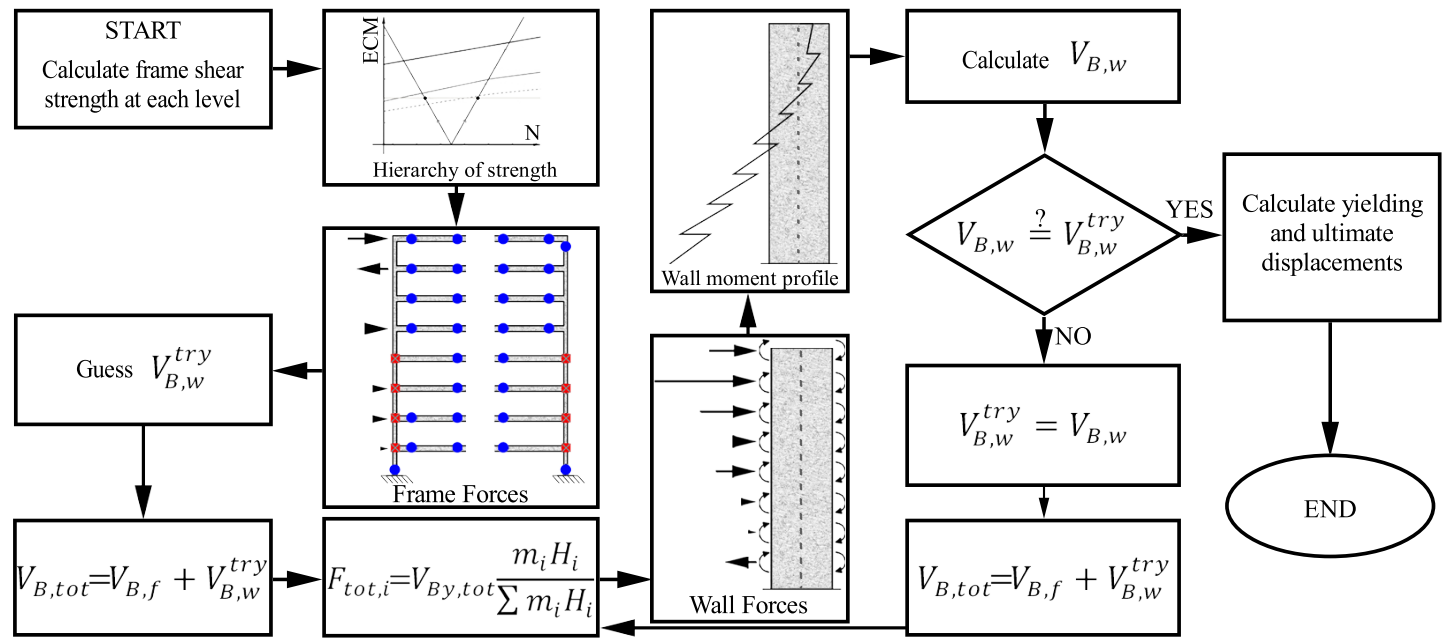

Figure 1 Determination of a dual system capacity curve according to the proposed

SLaMA procedure. For clarity, a single wall is considered.

\subsection{Member capacity evaluation}

Each member in the system (beams, columns, joints, walls) should be analysed using reliable models to 
retrieve their capacity (both in terms of forces/moments and displacements/rotations) and most probable failure mechanism. Herein, the suggestions included in NZSEE 2017 are summarised, for which a step-bystep numerical example is given in [Del Vecchio et al., 2017, 2018].

Frame system: Moment-Curvature analyses are carried out for beams and columns considering the gravity-induced axial loads. This is usually done using numerical approaches, but simplified analytical formulations can be adopted (e.g. Gentile et al., 2018a,b). Possible flange effect on the negative moment capacity of the beams, if appropriate, should be accounted for [Quintana-Gallo, 2014, NZSEE 2017]. The Force-Displacement relationship is obtained by means of a plastic hinge method (e.g. Priestley et al., 2007), for which the equivalent plastic hinge length depends on the clear span of the considered member, the hardening ratio of the steel and its strain penetration length. The eventuality of a lap-splice failure should be checked considering the ratio of the actual-to-required development length of the reinforcement (refer to NZSEE 2017 for example). According to the simplified methodology proposed in Eurocode 8 (EC8, 2005), if the ratio is less than one, the Moment-Curvature analysis should be repeated reducing the steel yielding stress according to this ratio. The curve should be modified according to Priestley et al., [1996] to account for strength degradation. Buckling of the longitudinal bars can be assessed according to Berry et al., [2005] while formulations based on Kowalsky and Priestley, [2000] can be adopted to consider possible shear failures. Conservatively, it is assumed that the shear failure of a frame member causes the attainment of the Ultimate Limit State, and therefore the behaviour of such members after shear failure is not explicitly considered.

Wall system: for each storey the behaviour of the wall is characterised as for the columns, by considering the portion of the wall from the top to the considered storey. However, the work by Krolicki et al., [2011] is adopted to evaluate the shear behaviour, since this formulation is specifically calibrated for $\mathrm{RC}$ walls. This allows to construct the moment capacity profile along the height of the wall (as suggested in NZSEE 2017) along with the probable failure mechanism at each storey. 
The shear capacity of the joint panels can be evaluated using principal (tensile and compressive) stresses approach and extensively validated (both experimentally and numerically) limits corresponding to first cracking and joint failure [Priestley 1997, Pampanin et al., 2002, 2006]. More details on the modelling of beam column joints, together with principal stress and drift limits at different performance levels, is given in Calvi et al., [2002], Pampanin et al., [2003].

\subsection{Hierarchy of strength for beam-column joint sub-assemblies}

The interaction between the frame members is evaluated assessing the hierarchy of strength of the beamcolumn joint sub-assemblies, defined as the portion of the frame enclosed by the contra-flexure points of the beams and the columns. The general process is summarised here, while detailed formulations can be found in Gentile et al., [2019a] and a detailed step-by-step example is given in Del Vecchio et al., [2017].

According to the original procedure proposed in Calvi et al., [2002] and Pampanin et al., [2007], the Equivalent Column Moment (ECM), $M_{c}^{*}$, is used as a common reference parameter to compare different members and failure modes. Taking beam flexural hinging as an example, it is possible to calculate, by means of equilibrium, how much is the moment in the column (ECM) when the beam is forming a plastic hinge. The Equivalent Column Moment is calculated for each member mechanism considered in Section 2.1, and this allows to define the ECM vs Axial load performance domain (Figure 2.a). In such diagram, the seismic demand is expressed as the variation of the column moment as a function of the variation of axial load with respect to the gravity load. This V-shaped approximation of the seismic demand is calculated firstly considering, by global equilibrium, the variation of axial load due to a unit base shear, and then considering a distribution of shear on the columns at the same storey. By intersecting demand and capacity, in both direction of the seismic action, the mechanism with the lowest ECM is likely to develop first. If such mechanism allows hardening, the next event in the hierarchy can activate, until the full strength of the sub-assembly is reached $\left(M_{c}^{*}\right)$. In Figure 2.a, the M-N performance domain indicates that a beam flexural hinge dominates the capacity of the selected sub-assembly, after the development of joint cracking. The 
yielding and ultimate drift of the member/mechanism that governs the capacity of the sub-assembly define the drift capacity of the sub-assembly. If link beams connect the wall(s) and the frame(s) systems, wallbeam sub-assemblies are also present. In such cases, it is reasonable to assume that the hierarchy of strength is governed by the failure mode of the (weaker) beam.

Figure 2.b shows a conceptual example of the evaluation of the hierarchy of strengths to a generic frame. If link beams connect the frame(s) and the wall(s) systems, the Equivalent Beam Moment $\left(M_{b}^{*}\right)$ calculated in the joint centroid is needed. Once the ECM capacity is known, this can be calculated by means of equilibrium of the joint - as the sum of the moments in the columns, calculated in the joint centroid, is equal to the sum of the moment in the beams - and assuming for simplicity that beam moments are equally distributed between the upper and lower columns. A past investigation on $40 \mathrm{RC}$ frame structures (Gentile et al., 2019a) shows that such a simplified assumption does not compromise the ability of SLaMA to capture the probable plastic mechanism, given the good match with plastic mechanisms calculated by means of refined numerical pushover analyses.

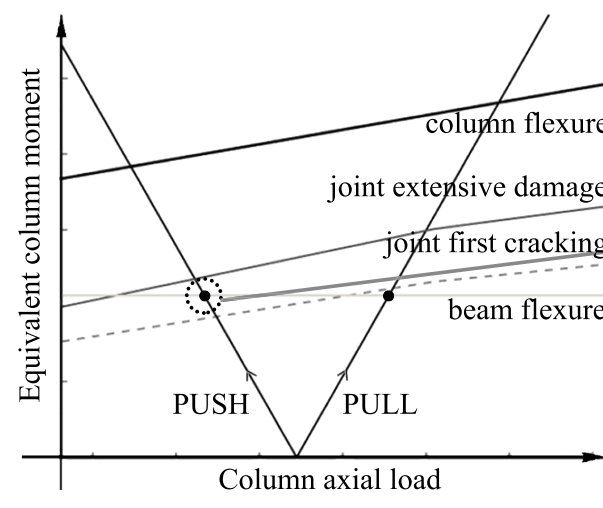

a) Performance domain

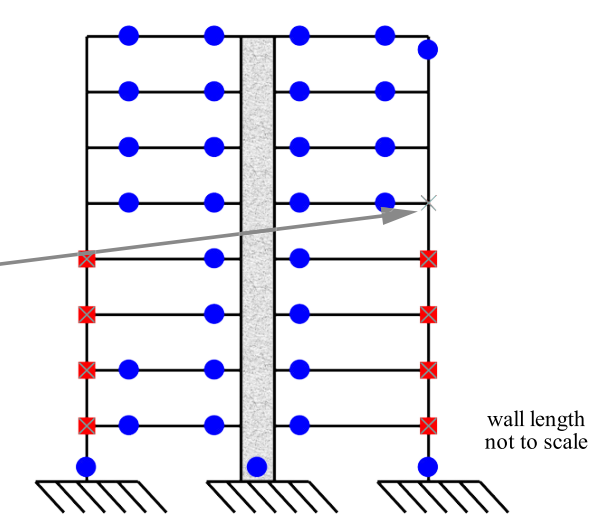

b) Hierarchy of strength

Figure 2 Example of hierarchy of strength and evaluation of local mechanisms in a dual system.

\subsection{Frame shear strength}

The frame storey shear strength at each storey, $V_{f, i}$, is calculated with Eq. 1, considering the Equivalent Column Moment at the top and bottom sub-assemblies $\left(M_{c, t o p}^{*}, M_{c, b o t}^{*}\right)$ for the $\mathrm{i}^{\text {th }}$ storey, excluding the 
beam-wall sub-assemblies from the summations. To calculate the frame strength at ground storey (frame base shear), the moment capacity of the ground columns $\left(M_{c}\right)$ is used, together with the Equivalent Column Moment in the top section of the ground columns (Eq. 2). The wall(s) base moment is excluded from this calculation, since it is considered explicitly in the assessment of the wall system(s).

$$
\begin{gathered}
V_{f, i}=\frac{\sum M_{c, t o p}^{*}+\sum M_{c, b o t}^{*}}{H_{\text {int }, i}} \\
V_{f, 1}=V_{B, f}=\frac{\sum M_{c, t o p}^{*}+\sum M_{c}}{H_{\text {int }, 1}}
\end{gathered}
$$

The portion of the inertia forces, $F_{f, i}$, related to the frame are then calculated recursively by subtracting the storey shear strength at a given storey to the shear strength of the storey below it (Eq. 3, where $\mathrm{n}$ is the top storey).

$$
\begin{gathered}
F_{f, n}=V_{f, n} \\
F_{f, i}=V_{f, i}-V_{f, i+1}
\end{gathered}
$$

\subsection{Contra-flexure height and wall shear strength}

For each wall, a trial value of the base shear associated to its flexural yielding or a brittle failure (bar buckling, shear), herein called yielding base shear, is firstly calculated $\left(V_{B, w}^{\text {try }}\right)$. A reasonable initial guess would be the wall yielding base shear strength considering a cantilever wall scheme. This is summed to the frame base shear to determine the total base shear of the structure corresponding to the yielding of the wall $\left(V_{B y, t o t}\right)$. With an assumption on their distribution, the total floor inertia forces $F_{t o t, i}$ are calculated distributing the total base shear along the elevation. In Eq. 4, a linear distribution of the inertia forces is assumed. The wall portion of the inertia forces is calculated by subtraction as per Eq. 5 .

$$
\begin{gathered}
F_{t o t, i}=V_{B y, t o t} \frac{m_{i} H_{i}}{\sum m_{i} H_{i}} \\
F_{w, i}=F_{t o t, i}-F_{f, i}
\end{gathered}
$$

The wall forces are used to calculate the bending moment demand profile on each wall. This is amplified 
until, for one point along the height, the moment demand equals the moment capacity profile, calculated in section 2.1. This allows to calculate the height for which the capacity of the wall is exceeded. The process is qualitatively shown in Figure 3. A new value of wall contribution to the base shear $\left(V_{B y, w}\right)$ is calculated and checked against the trial value. If the two values do not coincide, within a specified tolerance, the wall trial base shear is updated and the process is repeated until convergence. Typically, 2 or 3 iterations are sufficient. It is assumed that the hardening ratio of the wall is equal to the hardening ratio of the simplified Force-Displacement curve at the failure point. This allows to calculate the ultimate base shear of the wall(s), considering its ultimate displacement (section 2.5).

It is worth noting that if the frame and wall part are connected by link beams, the Equivalent Beam Moment related to the wall-beam sub-assemblies should also be considered in computing the wall moment profile. In such cases, the coupling effect (overturning moment capacity related to the link beams) is automatically accounted for in the calculation of the base shear of the wall(s).

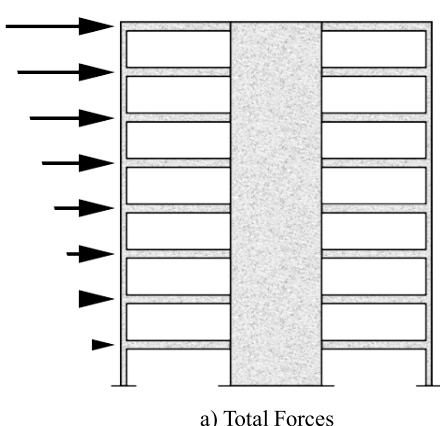

a) Total Forces

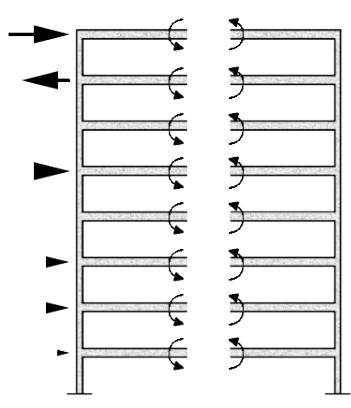

b) Frame Forces (depending on frame storey shear strength)

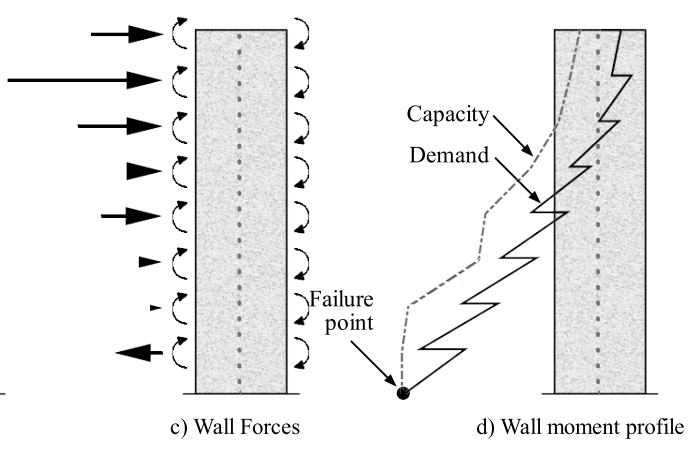

Figure 3 Wall moment profile in a dual system.

\subsection{Wall yielding and ultimate displacement}

The displacement profile of the dual system is strongly dependent on the contra-flexure height $\left(H_{C F}\right)$, i.e. the vertical distance between the ground and the point in which the wall moment (and curvature) is zero. This parameter is calculated from the wall(s) moment profile. If different walls are present, the highest contra-flexure height is assigned to the dual system, i.e. the strongest wall governs the behaviour. 
According to Sullivan et al., [2006], the yielding $\left(\Delta_{y, i}\right)$ and plastic displacement profile $\left(\Delta_{p, i}\right)$ are calculated with Equations 6 and 7, where $\phi_{w y}$ is the wall yield curvature, $\theta_{w p}$ is the plastic drift of the wall and $H_{i}$ is the height of the $\mathrm{i}^{\text {th }}$ storey from the foundation level. Hence, the yielding and ultimate displacement of the wall at the effective height are calculated with Eq. 8. It is now possible to describe the bi-linear capacity curve for each wall. The effective height of the system $\left(H_{e f f}\right)$ is calculated with Eq. 9 .

$$
\begin{aligned}
& \Delta_{y, i}= \begin{cases}\phi_{w y}\left(\frac{H_{i}^{2}}{2}-\frac{H_{i}^{3}}{6 H_{C F}}\right) & \text { for } H_{i} \leq H_{C F} \\
\phi_{w y}\left(\frac{H_{C F} H_{i}}{2}-\frac{H_{C F}^{2}}{6}\right) & \text { for } H_{i}>H_{C F}\end{cases} \\
& \Delta_{p, i}=\theta_{w p} H_{i} \\
& \Delta\left(H_{e f f}\right)=\frac{\sum m_{i} \Delta_{i}^{2}}{\sum m_{i} \Delta_{i}} \\
& H_{e f f}=\frac{\sum m_{i} \Delta_{i} H_{i}}{\sum m_{i} \Delta_{i}}
\end{aligned}
$$

\subsection{Frame yielding and ultimate displacement}

It is deemed that the yielding of the frame portion of a dual system can be reasonably represented by the first base column that yields (with drift $\theta_{c y}$ ), and the related displacement $\left(\Delta_{y, f}\right)$ is calculated with Eq. 10. On the other hand, the ultimate displacement of the frame $\left(\Delta_{u, f}\right)$ is considered to occur when the first subassembly in the system reaches its ultimate drift $\left(\theta_{s u b, u}\right)$, including the wall-frame sub-assemblies, if present. Hence, according to the calculated hierarchy of strength, the frame ultimate displacement is calculated with Eq. 11. Finally, the bilinear representation of the capacity curve of the frame portion is obtained (Figure 5).

$$
\begin{gathered}
\Delta_{y, f}=\min \left(\theta_{c y}\right) \cdot H_{e f f} \\
\Delta_{u, f}=\min \left(\theta_{s u b, u}\right) \cdot H_{e f f}
\end{gathered}
$$

If link beams are present, their ultimate drift might need to be reduced to indirectly consider the additional drift demand induced by the wall (see Figure 4). A tentative procedure is proposed to consider 
this effect. Initially, the ultimate drift of the sub-assembly $\left(\theta_{s u b, u}\right)$ is "imposed" to the wall (guessed value). The uplift $\Delta_{1}$ and the wall-induced drift on the link beam $\theta_{b, a d d}$ are calculated with Equations 12 and 13 , respectively. The "corrected" ultimate drift of the sub-assembly, $\theta_{u, s u b}^{*}$, is calculated with Eq. 14 and checked against the guessed value. The imposed drift on the wall is updated using $\theta_{u, s u b}^{*}$, and the process is repeated until convergence. An estimate of the neutral axis depth (at wall yielding) to wall length ratio, $c / l_{w}$, is needed in Eq. 12 .

It is worth mentioning that is unlikely that the Ultimate Limit State (ULS) of the dual system is caused by the attainment of the ultimate displacement in the frame system [NZSEE 2017]. Therefore, it is unlikely that an error on the frame ultimate displacement can affect the definition of the dual system capacity curve. To keep the calculations as simple as possible, it is suggested to firstly calculate the frame ultimate displacement without this "correction" and to use this iterative procedure only if the wall and frame ultimate displacements are particularly similar.

$$
\begin{gathered}
\Delta_{1}=\left(l_{w}-c\right) \tan \left(\theta_{p, w}\right) \\
\theta_{b, a d d}=\frac{\Delta_{1}}{L_{b}} \\
\theta_{u, s u b}^{*}=\theta_{u, s u b}-\theta_{b, a d d}
\end{gathered}
$$

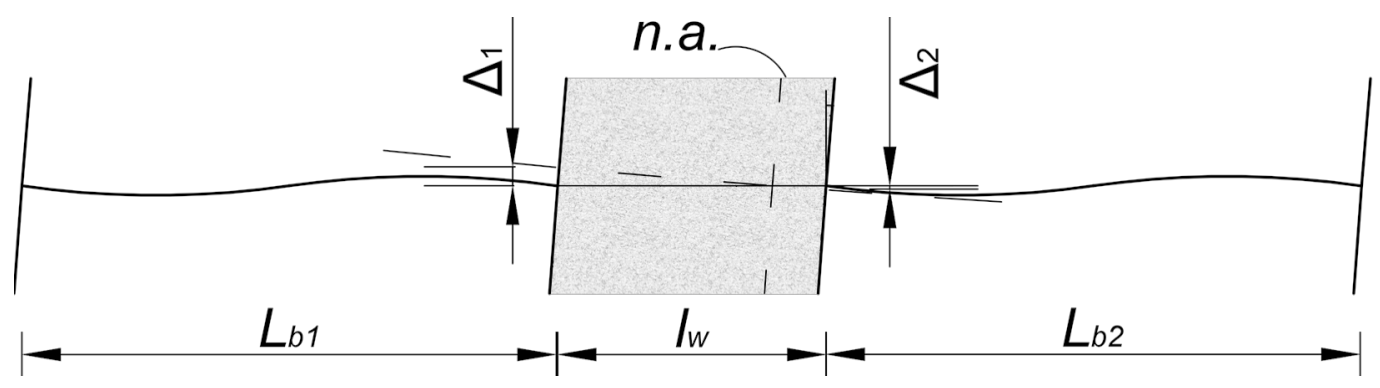

Figure 4 Wall-induced drift on link beams.

\subsection{Capacity curve of the structure}

The frame and wall contributions are summed up to obtain the total capacity curve of the system (Figure

5). The ultimate displacement $\left(\Delta_{u}\right)$ is assumed to be the ultimate displacement of the frame or the wall, 
whichever occurs first. Finally, if a bi-linear approximation of the curve is needed, the first branch should be extrapolated until reaching the maximum base shear. As suggested in Paulay [2001], such extrapolation allows to have a better estimation of the yield displacement, without jeopardising the overall representation (due to the negligible increase in the area under the curve).

It is worth mentioning that the SLaMA-based capacity curve can be also adopted to derive fragility functions (that represent the exceeding probability of a damage state given the ground motion intensity measure). Although such concept is outside the scope of this paper, literature approaches can be used such as SPO2FRAG (Baltzopulos et al., 2017) or FRACAS (Rossetto et al., )

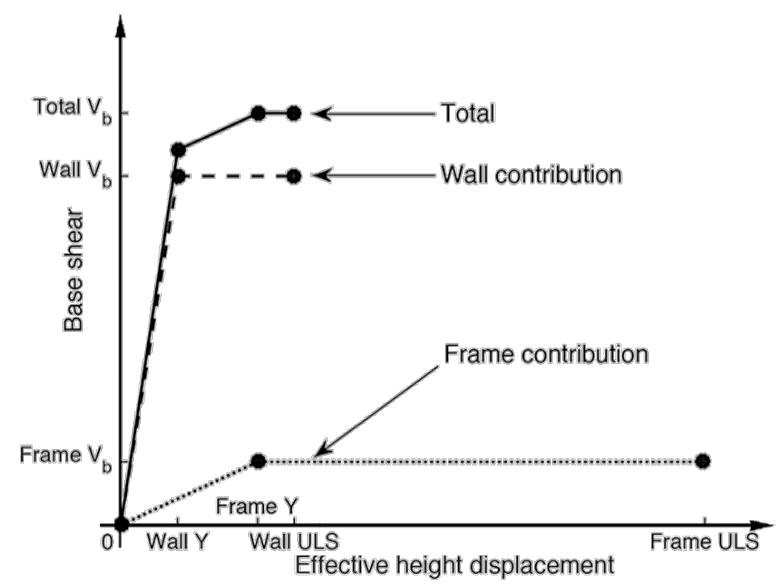

Figure 5 Capacity curve of the wall-frame structure: total and individual contribution.

\subsection{Other Displacement-Based Assessment parameters}

Once the force-displacement capacity curve of the dual system is known, according to a capacity spectrum approach, the performance point (for a given earthquake intensity) can be evaluated, together with the seismic capacity-to-demand ratio. As an example, the percentage of New Building Standard (\%NBS, NZSEE 2017) is discussed here, although other methods might be chosen (e.g. N2 method, Fajfar and Fischinger, 1988). The $\% \mathrm{NBS}$ is defined as the displacement ratio of the capacity of the building to the minimum required by the Building Code (in correspondence of the effective period of the building $T_{e}$ ) for a similar new building. 
Firstly, the force-displacement capacity curve is expressed in terms of capacity spectrum by dividing the base shear by the effective mass at the ultimate displacement $\left(m_{e f f}\right)$, calculated according to Eq. 15. The effective period of the dual system, in correspondence of its ultimate displacement, is calculated according to Eq. 16. In turn, this allows to calculate (according to Sullivan et al., [2006]) the hysteretic components of the Equivalent Viscous Damping (EVD) related to the wall $\left(\xi_{\text {hyst,w }}\right.$, Eq. 17) and frame ( $\xi_{\text {hyst }, f}$, Eq. 18), where $\mu_{w}$ and $\mu_{i}$ are the ductility demand on the wall and frame and $r$ is the hardening ratio of the dual system. Adding the elastic component $(5 \%)$, the total EVD are calculated $\left(\xi_{w}, \xi_{f}\right)$, for the wall and the frame components. Finally, Eq. 19 allows to calculate the Equivalent Viscous Damping related to the equivalent SDOF structure $\left(\xi_{S D O F}\right)$, where $M_{w}$ is the sum of the wall base moments and $M_{O T, f}$ is the overturning moment related to the frame part.

On the other hand, the elastic acceleration-displacement spectrum (at Life Safety intensity), is multiplied by the damping-dependent factor $\eta$ (Eq. 20) to represent the inelastic demand spectrum. The inelastic displacement demand corresponding to the effective period is therefore calculated $\left(\Delta_{\text {dem }}\right)$ and the $\%$ NBS is calculated according to Eq. 21 . A value greater than $100 \%$ indicates that the structure is able to withstand the seismic demand.

$$
\begin{gathered}
m_{e f f}=\frac{\sum m_{i} \Delta_{i}}{\Delta_{u}} \\
T_{e}=\frac{V_{B, u}}{m_{e f f} \Delta_{u}} \\
\xi_{\text {hyst }, w}=\frac{95}{1.3 \pi}\left(1-\frac{1}{\mu_{w}^{0.5}}-0.1 r \mu_{w}\right)\left(1+\frac{1}{\left(T_{e}+0.85\right)^{4}}\right) \\
\xi_{\text {hyst }, f}=\frac{120}{1.3 \pi}\left(1-\frac{1}{\mu_{f}^{0.5}}-0.1 r \mu_{f}\right)\left(1+\frac{1}{\left(T_{e}+0.85\right)^{4}}\right) \\
\xi_{S D O F}=\frac{M_{w} \xi_{w}+M_{O T, f} \xi_{f}}{M_{w}+M_{O T, f}} \\
\eta=\left(\frac{7}{2+\xi_{S D O F}}\right)^{\alpha}, \text { where } \alpha=0.5 \text { for far field and } \alpha=0.25 \text { for near fault motions }
\end{gathered}
$$




$$
\% N B S=\frac{\Delta_{u}}{\Delta_{d e m}} \cdot 100
$$

\section{Validation of the proposed procedure}

The proposed SLaMA procedure has been applied to 28 case studies, comparing the results with refined numerical pushover analyses. The dataset is divided in three groups, obtained with selected modifications with respect to a reference structure (case study \#1). It is worth mentioning that the properties of the materials for all the case studies are reported in Section 3.3. Since this work aims to propose an analytical procedure to calculate the non-linear capacity curve of dual systems, only non-linear static analyses are carried out.

\subsection{Case study \#1}

The starting point (case study \#1) in the dataset is an 8-storey building, regular in geometry, composed by two parallel 2-bay dual systems (with link beams) in the longitudinal direction and two cantilever walls in the transverse one. The inter-storey height is equal to $3.05 \mathrm{~m}$, while the two bays in the dual system are $7.15 \mathrm{~m}$ long, connected by a central $6.1 \mathrm{~m}$ long wall. This building is meant to represent a typical $1970 \mathrm{~s}$ RC construction, without capacity design principles and comprehensive seismic details.

Figure 6 shows the plan and elevation views of the building, together with the geometrical dimensions and the longitudinal reinforcement ratios $(\rho)$ of the members. The transverse reinforcement ratio for beams and columns is equal to $\rho_{t}=0.2 \%$ and $\rho_{t}=0.7 \%$ respectively, while $\phi 10 \mathrm{~mm}$ stirrups (hoops), spaced at $254 \mathrm{~mm}$, are provided for the $6.1 \mathrm{~m}$-long wall. No joint stirrups are provided, therefore the expected plastic mechanism in the frame part is a Mixed-Sway (MS), in which either flexural plastic hinges and member or joint shear failures can occur. 


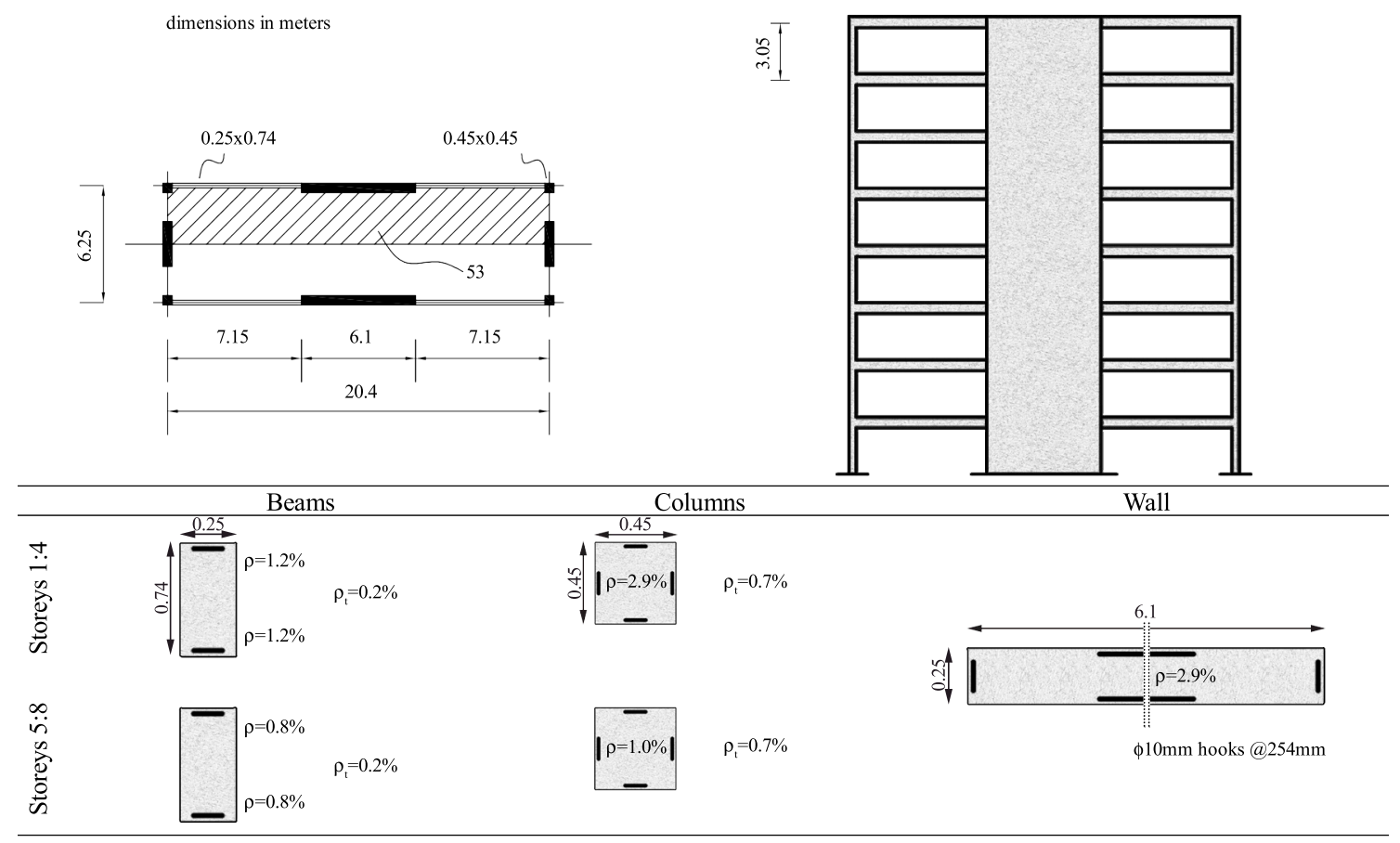

Figure 6. Case study \#1: plan, elevation and detailing of the members.

The storey seismic weight is determined considering a concrete density equal to $25 \mathrm{kN} / \mathrm{m}^{3}$, superimposed dead load equal to $0.5 \mathrm{kPa}$, a live load (factored) equal to $0.9 \mathrm{kPa}$. The total floor area is equal to $106 \mathrm{~m}^{2}$, hence the tributary area for one single dual system is $53 \mathrm{~m}^{2}$. This leads to a total floor weight of $466.8 \mathrm{kN}$, referred to one dual system. The column axial loads were estimated by means of tributary area considerations. It is noteworthy that, since no stiffness/strength eccentricity is present, the analyses are restricted to one single dual system in the longitudinal direction.

\subsection{Case study groups}

Three groups of case studies have been created starting from the basic case study \#1 (Figure 7).

Group 1 - This is composed of 8-storey, 2-bays dual systems with a geometry equal to case \#1. In this group, the main changing parameters are the expected plastic mechanism of the frame part (4 alternatives) and the wall/frame strength proportions (4 alternatives). Considering all the possible combinations, 16 case studies are defined. 
Apart from the Mixed-Sway case (section 3.1), three alternatives are provided for the frame hierarchy of strength. In the Beam-Sway (BS) alternative, $5 \phi 12 \mathrm{~mm}$ stirrups are provided for all the joints. Therefore, the expected plastic mechanism involves plastic hinges forming in all beam ends and at the base section of the ground columns. The Column-Sway ground floor (CSgf) alternative has been created starting from the BS by providing square cross-section with a $300 \mathrm{~mm}$-side for all the columns and reducing the moment capacity of the ground columns. The ratio of the yielding moment of these columns, $\mathrm{M}_{\mathrm{cy}}$, to the adjacent beam yielding moment, $\mathrm{M}_{\mathrm{by}}$, is equal to 0.45 , therefore plastic hinges are expected for such columns at both ends. A similar process has been adopted to create the Column-Sway mid height (CSmh) alternative, by providing $300 \mathrm{~mm}$-side for all the columns and weakening the columns at the $5^{\text {th }}$ storey (300mm-side for all the columns $\mathrm{M}_{\mathrm{cy}} / \mathrm{M}_{\mathrm{by}}=0.45$ ). In this group, the yielding moment of the wall is equal to $100 \%, 75 \%, 50 \%$ and $35 \%$ of the wall yielding moment in case study $\# 1$, leading to a wide range of wallto-frame strength ratios.

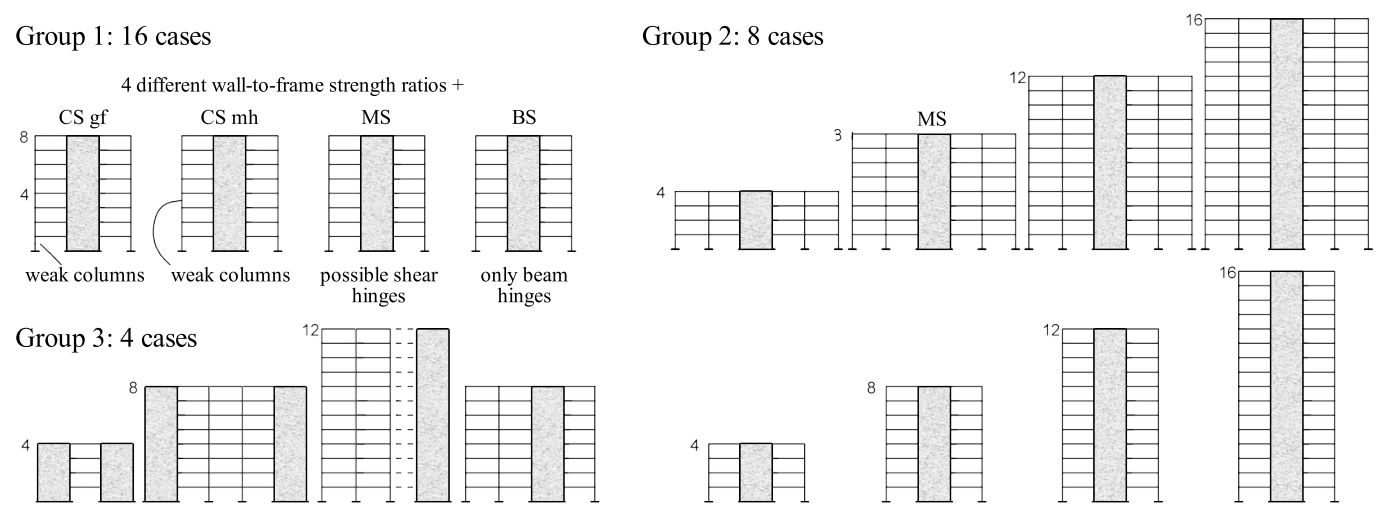

Figure 7 Case study groups.

Group 2 - The second group of buildings (Figure 7) is considered to study the influence of the "slenderness" of the structure (height to length ratio) on the frame/wall interaction and consequently the contra-flexure height of the wall. The group is composed of 8 dual systems with 4, 8, 12 or 16 storeys. Four case studies have a geometry equal to case study \#1 while for the remaining ones two more $7.15 \mathrm{~m}$ frame spans are added. 
A single wall is provided for such cases (longitudinal reinforcement ratio equal to $1.3 \%$ ), located at the centre and connected with link beams to the frame part. The reinforcement ratios of all the beams and columns is equal to $1.4 \%$ and $2.4 \%$, respectively. No stirrups are provided in the joint panels.

Group 3 - The third group aims to analyse different geometrical configurations and is composed of 4 case studies. The first case study is a 4-storey coupled wall system, with two $6.1 \mathrm{~m}$-long walls and a net $6.9 \mathrm{~m}$ long span. The second case study is an 8-storey wall-frame-wall system with two 6.1m-long walls and three $6.7 \mathrm{~m}$-long frame bays. The third case study is a 12 -storey 2-bays $20.4 \mathrm{~m}$-long frame connected in parallel to a $6.1 \mathrm{~m}$-long wall, without linking beams. The fourth case study is an asymmetric linked dual system with a $6.1 \mathrm{~m}$-long central wall, and two $7.5 \mathrm{~m}$-long frame bays on each side. The walls in this group are provided with a reinforcement ratio equal to $0.5 \%$ and $\phi 10254 \mathrm{~mm}$-spaced stirrups (hoops). The reinforcement ratios of all the $0.74 \mathrm{mx} 0.25 \mathrm{~m}$ beams and $0.5 \mathrm{mx} 0.5 \mathrm{~m}$ columns is equal to $1.4 \%$ and $2.4 \%$, respectively. No stirrups are provided in the joint panels.

\subsection{Assumptions for the evaluation of the member capacity}

The material properties chosen for the parametric study are meant to represent typical values for existing RC buildings. Steel is modelled according to King et al. [1986] and considering $E_{s}=200000 \mathrm{MPa}, f_{y}=300$ $\mathrm{MPa}, f_{u}=390 \mathrm{MPa}$ and an ultimate strain equal to $\varepsilon_{s u}=0.06$. A strength equal to $f_{c}^{\prime}=25 \mathrm{MPa}$ is used for concrete, and elastic modulus equal to $E_{c=} 5000 \sqrt{f_{c}^{\prime}}$. The concrete backbone curve refers to Mander et al., [1988] and the ultimate strain $\left(\varepsilon_{c u}\right)$ has been calculated accordingly. It is worth mentioning that $\varepsilon_{c u}$ ranges between 0.006 , for poorly confined members in the CS groups, and 0.02 , conservatively considered as an upper bound value for the members in the BS group. The characterisation of beams, columns, joints and walls and the hierarchy of strength calculations are carried out according to Sections 2.1 and 2.2 and using the software Cumbia [Montejo and Priestley, 2007]. The calculated negative moment capacity of the beams was increased by $30 \%$ to approximately consider a potential flange effect. 


\subsection{Numerical modelling strategy}

For each case study a pushover analysis has been performed with the FEM software Ruaumoko [Carr, 2016], adopting an extensively experimentally-validated lumped plasticity approach [Magenes and Pampanin, 2004] shown in Figure 8. The analyses are conducted in displacement-control protocol (control node on the roof) with linear force profile and neglecting P- $\Delta$ effects, consistently with the assumptions in SLaMA. Floor slabs are considered to be rigid in plane and rigid link elements are used to connect the link beams to the wall centreline. Fully fixed boundary conditions are considered at the base of the building. The plot of the capacity curves is terminated when the first member in the system reaches its ultimate displacement capacity.

Beams were modelled by means of mono-dimensional Giberson elements [Sharpe, 1976]. Their behaviour is modelled by means of bi-linear Moment-Curvature relationships and plastic hinge length (see Section 2.1). On the other hand, columns and walls are characterised by Moment-Axial load interaction diagram. Wall elements were discretised having an element for each storey. To model the beam-column joints, the rigid arms related to beams and columns are connected through rotational springs (scissors model) with tri-linear constitutive relationship. More details about this modelling strategy are given in Gentile et al., [2019a]. A detailed description of the adopted strength and deformation capacity of the joint panels is given in NZSEE 2017, Pampanin et al., 2002, Calvi et al., 2002. 


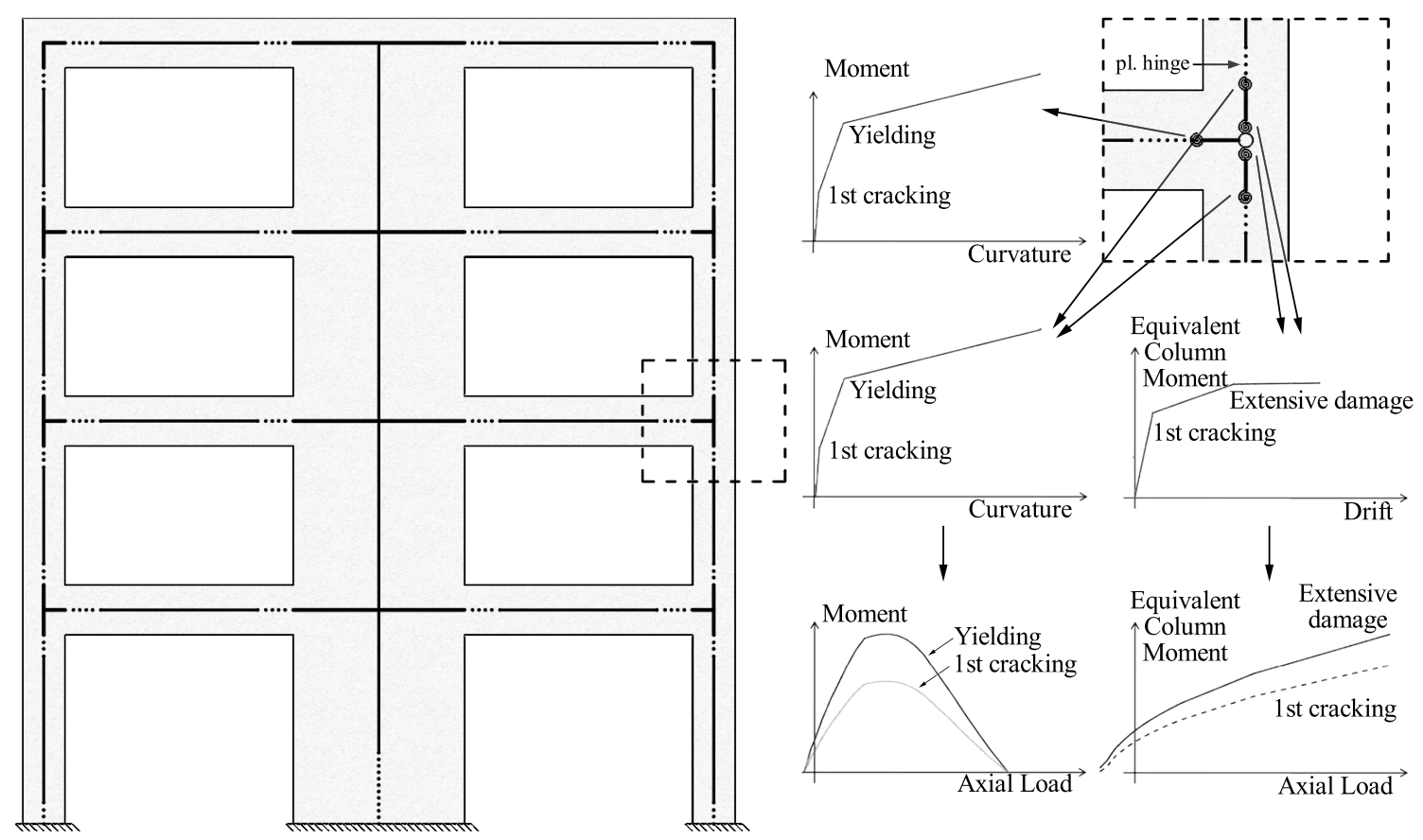

Figure 8. Numerical modelling strategy based on lumped plasticity approach.

\section{Discussion of the results}

The focus of this parametric analysis is to validate the proposed SLaMA procedure for dual systems. The general trends in the three groups are firstly discussed through the graphical results for some representative case studies (A detailed report on the numerical results for all case studies can be found in Gentile [2017]). For the sake of synthesis, the rest of the results is summarised in table form and discussed in section 4.4. The reliability of the procedure is measured by means of the percentage error $\left(\operatorname{Err}(\%)=\frac{S L a M A-P . O}{P . O .}\right)$ calculated for selected parameters: yielding and ultimate displacement of the frame and the wall portions, the ultimate base shear and the contra-flexure height.

\subsection{Group 1: wall/frame strength proportions}

Figure 9 shows the comparison between the SLaMA and the numerical pushover curves for three selected cases, namely Mixed-Sway Wall 100\% (\#1), Beam-Sway Wall 50\% (\#7) and Column-Sway (mid height, \#12) Wall 35\%. For the same cases, Figure 10 shows a snapshot of the plastic mechanism at the ULS, extracted from the numerical analyses. The error trends between analytical and numerical results for the 
entire Group 1, composed of 16 case studies, are summarised in Table 1 (a positive value indicates an overprediction of SLaMA with respect to the numerical pushover).

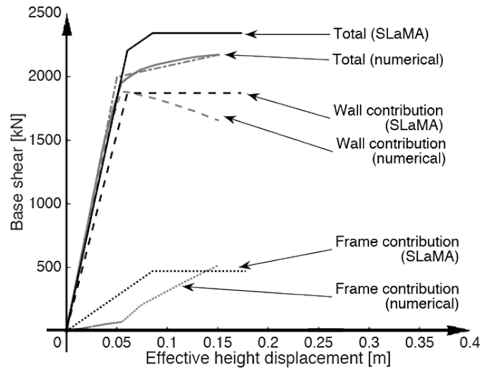

a) WAll 100\% Mixed Sway (\#1)

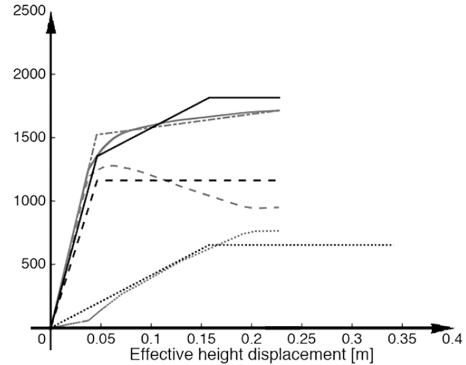

b) WAll 50\% Beam-Sway (\#7)

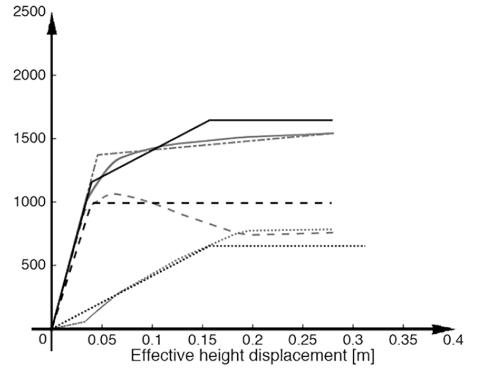

c) Wall 35\% Column-Sway mh (\#12)

Figure 9. Capacity curves for three case studies in Group 1 (with disaggregation of the wall and frame contribution).

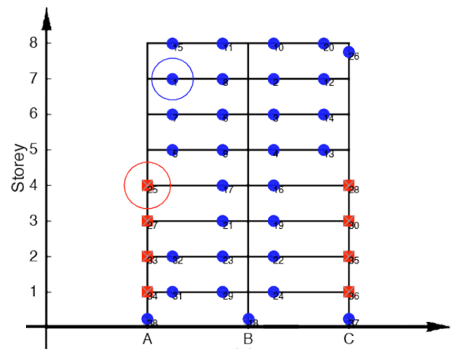

a) WAll 100\% Mint Mixed Sway (\#1)

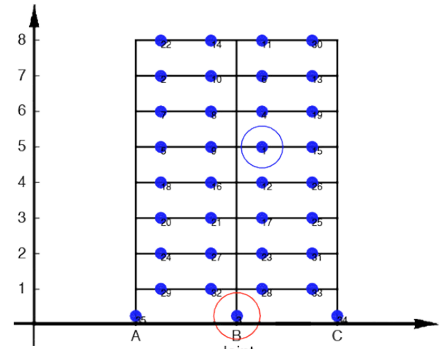

b) WAll 50\% Beaint Beam-Sway (\#7)

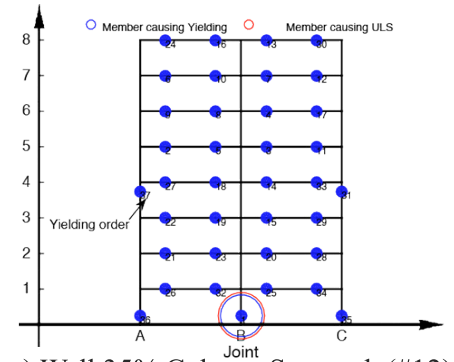

c) Wall 35\% Column-Sway mh (\#12)

Figure 10. Plastic mechanism at ULS for three case studies in Group 1.

As shown in Figure 9 and Table 1, regardless of the hierarchy of strength in the frame part and the moment capacity of the wall, there is a particularly good match between the SLaMA and the pushover curves. In particular, the wall ultimate displacement, which causes the ULS of the structure for the entire group, is particularly close (max $3.7 \%$ over-prediction) to the pushover prediction while the error on the frame ultimate displacement is greater (between $8.7 \%$ and $20.6 \%$ under-prediction). An analogous pattern is found when referring to wall and frame yielding displacement.

The ultimate base shear is slightly over-predicted $(\max 8.4 \%)$ and this is related to the compatibility forces between wall and frame [Simonini et al., 2012]. In particular, after the formation of the wall base hinge the frame is forced to change its deformed shape. Hence, the diaphragm will cause a redistribution of actions from the wall to the frame, decreasing the demand in the former and increasing it in the latter. 
The SLaMA procedure is not able to capture this behaviour, leading to an over-prediction of the wall base shear which is partially counterbalanced by an under-prediction of the frame base shear. The final result is a slight over prediction of the total base shear. Since compatibility forces - due to the interaction between walls and frame - are not computed in SLaMA, the individual contribution of wall and frame to the base shear capacity curves are not correctly estimated. However, those contributions can be considered according to the analytical procedure proposed in Rutenberg, [2004].

As shown in Figure 10, the plastic mechanism at ULS, extracted from the numerical models, indicates that the frame portion is able to develop its full shear strength at every storey, regardless on the hierarchy of strength in the sub-assemblies. This is a first confirmation of the aforementioned basic hypothesis on which the SLaMA procedure herein presented is based.

Table 1. Group 1: error trends. (SLaMA-P.O.)/P.O. [\%].

\begin{tabular}{lrrrrrr}
\hline \multicolumn{1}{c}{ CASE } & $\begin{array}{c}\operatorname{Err}\left(\delta_{\mathrm{y}, \mathrm{f}}\right) \\
\text { Frame yield } \\
\text { displacement }\end{array}$ & $\begin{array}{c}\text { Errame }\left(\delta_{\mathrm{u}, \mathrm{f}}\right) \\
\text { displacement }\end{array}$ & $\begin{array}{c}\operatorname{Err}\left(\delta_{\mathrm{y}, \mathrm{w}}\right) \\
\text { Wall yield } \\
\text { displacement }\end{array}$ & $\begin{array}{c}\text { Err }\left(\delta_{\mathrm{u}, \mathrm{w}}\right) \\
\text { Wall ultimate } \\
\text { displacement }\end{array}$ & $\begin{array}{c}\text { Err }\left(\mathrm{V}_{\mathrm{b}, \mathrm{ULS}}\right) \\
\text { Total ultimate } \\
\text { base shear }\end{array}$ & $\begin{array}{c}\text { Err }\left(\mathrm{H}_{\mathrm{CF}}\right) \\
\text { contra-flexure } \\
\text { height @ULS }\end{array}$ \\
\hline 1. Mixed-Sway wall 100\% & -33.6 & -14.8 & 11.1 & 0.0 & 8.3 & -0.8 \\
2. Mixed-Sway wall 75\% & -34.1 & -12.9 & 19.6 & 0.5 & 7.5 & -1.2 \\
3. Mixed-Sway wall 50\% & -33.3 & -12.5 & 18.4 & 3.7 & 1.5 & -1.7 \\
4. Mixed-Sway wall 35\% & -32.8 & -12.1 & 18.2 & -0.4 & 8.4 & -1.4 \\
5. Beam-Sway wall 100\% & -20.0 & -10.9 & 15.4 & 3.0 & 6.9 & -5.7 \\
6. Beam-Sway wall 75\% & -19.3 & -10.9 & 19.6 & 1.6 & 6.4 & -0.3 \\
7. Beam-Sway wall 50\% & 22.2 & 14.4 & -17.4 & 0.9 & -5.6 & 0.6 \\
8. Beam-Sway wall 35\% & -16.0 & -12.9 & 18.2 & -1.8 & 6.7 & 5.2 \\
9. C-Sway (mh) wall 100\% & -27.5 & -8.7 & 17.6 & 3.0 & 5.9 & -1.8 \\
10. C-Sway (mh) wall 75\% & -27.1 & -9.0 & 19.6 & 1.1 & 5.9 & -0.1 \\
11. C-Sway (mh) wall 50\% & -23.5 & -9.3 & 21.6 & 1.8 & 5.8 & 0.7 \\
12. C-Sway (mh) wall 35\% & -21.1 & -10.3 & 21.9 & 0.7 & 6.6 & 5.8 \\
13. C-Sway (gf) wall 100\% & -19.2 & -17.6 & 17.6 & 3.0 & 6.8 & 8.2 \\
14. C-Sway (gf) wall 75\% & -18.5 & -18.6 & 19.6 & 1.1 & 6.3 & 0.1 \\
15. C-Sway (gf) wall 50\% & -16.0 & -19.3 & 21.1 & 0.4 & 5.8 & 0.6 \\
16. C-Sway (gf) wall 35\% & -15.1 & -20.6 & 18.2 & -1.1 & 6.7 & 4.7 \\
\hline Average of absolute values & 23.7 & 13.4 & 18.4 & 1.5 & 6.3 & 2.4 \\
\hline
\end{tabular}

\subsection{Group 2: contra-flexure height investigation}

Group 2 is defined to analyse the robustness of the proposed SLaMA procedure with regard to the slenderness of the structure and, consequently, to the contra-flexure height of the wall(s). Hence, along with 
the capacity curves (Figure 11) of two selected cases (\#17 and \#24) in this group, the SLaMA-based wall moment profile at ULS is compared to the numerically-based one (Figure 12). The error trends for this group are summarised in Table 2.

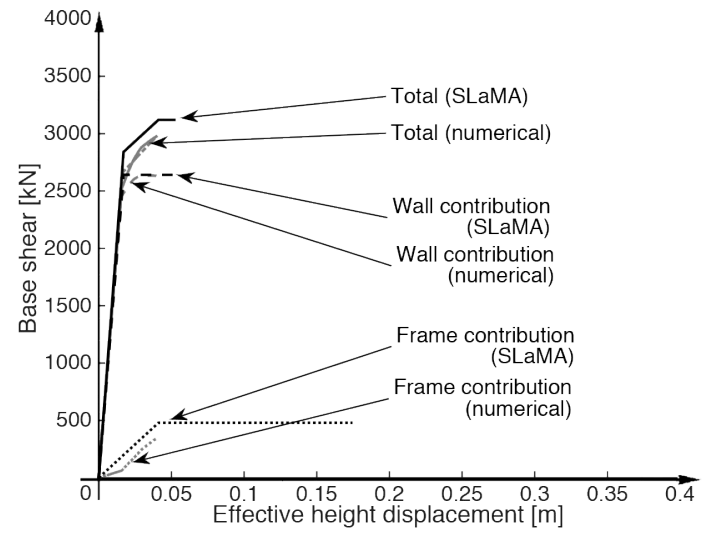

a) 4 storeys 2 bays (\#17)

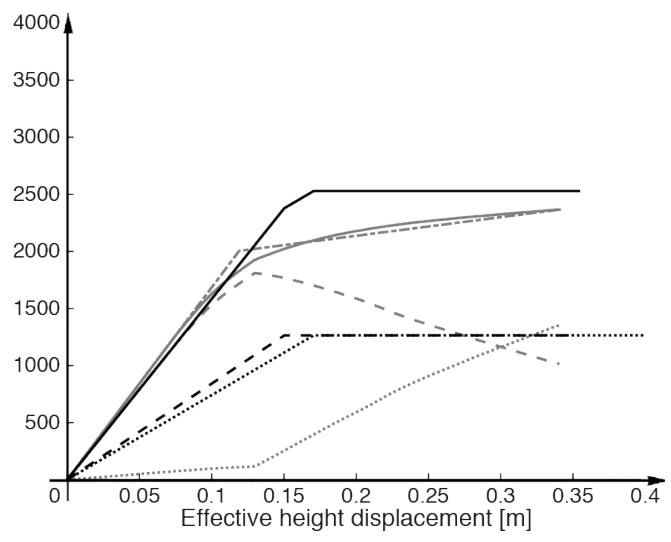

b) 16 storeys 4 bays (\#24)

Figure 11. Capacity curves for two case studies in group 2 (with disaggregation of the wall and frame contributions).

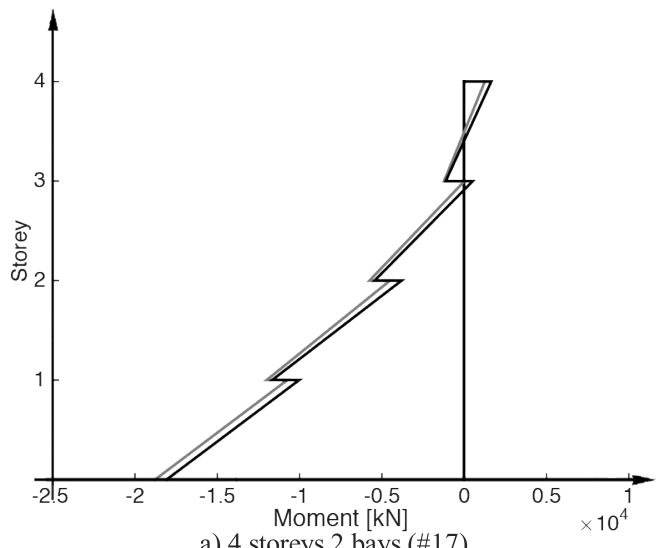

a) 4 storeys 2 bays (\#17)

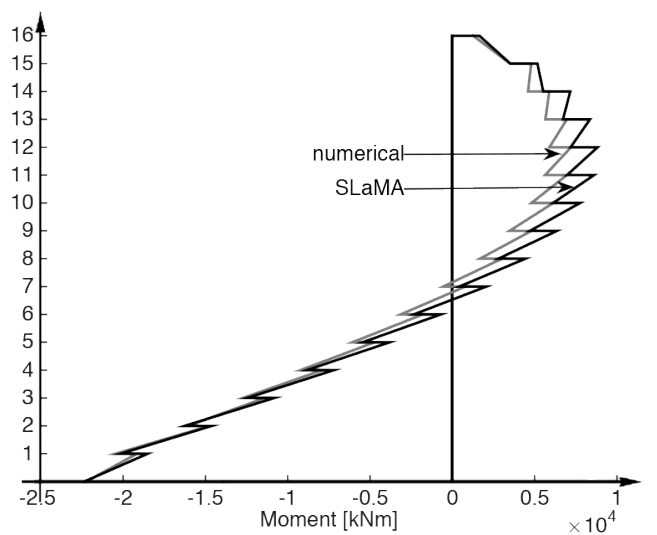

b) 16 storeys 4 bays (\#24)

Figure 12. Wall moment profile at ULS for two case studies in group 2.

The proposed SLaMA leads to particularly accurate predictions for this group, when compared with the numerical results. The base shear at ULS is over-predicted with an average 5.6\% error (maximum $7.0 \%$ ) for all the considered case studies. The wall yielding and ultimate displacement are captured with great accuracy (maximum $13.2 \%$ and $2.6 \%$ errors, on average). On the other hand, less accuracy is recorded in the determination of the yielding and ultimate displacements of the frame portion $(44.6 \%$ and $8.8 \%$ errors, on average). However, for no case this affects the global capacity curve, since the ULS of the structure is 
caused by the ultimate curvature at the base of the wall (which, with respect to columns/beams, have similar limits on the concrete ultimate strain and a much greater length of the cross-section). As mentioned in Section 4.1, the individual contributions curves should not be relied upon, and this is particularly evident in the 16-storeys 4-bays building (Figure 11.b).

It is deemed that the contra-flexure height is the most important parameter to discuss for this group because it represents the wall-to-frame interaction in a dual system. Figure 12 shows the comparison of the wall moment profile at the ULS for the 4-storeys, 2-bays and the 16-storeys-4bays cases. The results, which are qualitatively similar for all the case studies, show that there is an excellent match between the proposed SLaMA and the numerical results $(3.7 \%$ error, on average).

Table 2. Group 2: error trends. (SLaMA-P.O.)/P.O. [\%].

\begin{tabular}{lrrrrrr}
\hline \multicolumn{1}{c}{ CASE } & $\begin{array}{c}\operatorname{Err}\left(\delta_{\mathrm{y}, \mathrm{f}}\right) \\
\text { Frame yield } \\
\text { displacement }\end{array}$ & $\begin{array}{c}\operatorname{Err}\left(\delta_{\mathrm{u}, \mathrm{f}}\right) \\
\begin{array}{c}\text { Frame ultimate } \\
\text { displacement }\end{array}\end{array}$ & $\begin{array}{c}\operatorname{Err}\left(\delta_{\mathrm{y}, \mathrm{w}}\right) \\
\text { Wall yield } \\
\text { displacement }\end{array}$ & $\begin{array}{c}\operatorname{Err}\left(\delta_{\mathrm{u}, \mathrm{w}}\right) \\
\text { Wall ultimate } \\
\text { displacement }\end{array}$ & $\begin{array}{c}\text { Err }\left(\mathrm{V}_{\mathrm{b}, \mathrm{ULS}}\right) \\
\text { Total ultimate } \\
\text { base shear }\end{array}$ & $\begin{array}{c}\operatorname{Err}\left(\mathrm{H}_{\mathrm{CF}}\right) \\
\text { contra-flexure } \\
\text { height @ULS }\end{array}$ \\
\hline 17. 4-storey 2-bays & -34.9 & -5.9 & 6.3 & 0.0 & 1.9 & -3.1 \\
18. 8-storey 2-bays & -42.8 & 6.4 & 14.6 & 3.2 & 6.2 & -2.8 \\
19. 12-storey 2-bays & -56.1 & -5.8 & 17.0 & -5.2 & 7.5 & -5.5 \\
20. 16-storey 2-bays & -50.7 & -4.7 & 14.6 & 3.6 & 5.7 & -4.2 \\
21. 4-storey 4-bays & -31.0 & 32.1 & 13.3 & 0.0 & 4.6 & -3.5 \\
22. 8-storey 4-bays & -40.9 & 3.5 & 11.4 & 1.6 & 6.4 & -4.0 \\
23. 12-storey 4-bays & -47.0 & -4.4 & 13.3 & -2.2 & 5.9 & -2.9 \\
24. 16-storey 4-bays & -53.2 & -7.2 & 15.4 & 5.0 & 7.0 & -3.8 \\
\hline Average of abs. val & $\mathbf{4 4 . 6}$ & $\mathbf{8 . 7}$ & $\mathbf{1 3 . 2}$ & $\mathbf{2 . 6}$ & $\mathbf{5 . 6}$ & $\mathbf{3 . 7}$ \\
\hline
\end{tabular}

\section{3. $3^{\text {rd }}$ group: other configurations}

The results for the third group (Table 3) show, at least qualitatively, that the previously calculated error trends are also valid for coupled walls, wall-frame-wall systems, uncoupled dual systems (without link beams) and asymmetric cases. In fact, a slight over-prediction (max $3.3 \%$ ) is seen for the ultimate base shear, a fair estimation of the wall yielding and ultimate displacement (14.9\% and $13.0 \%$, on average), a higher error for the frame yielding and ultimate displacement (34.9\% and $14.1 \%$, on average) and a particularly accurate prediction of the contra-flexure height (max $0.6 \%$ error). 
Table 3. Group 3: error trends. (SLaMA-P.O.)/P.O. [\%].

\begin{tabular}{lrrrrrr}
\hline \multicolumn{1}{c}{ CASE } & $\begin{array}{c}\operatorname{Err}\left(\delta_{\mathrm{y}, \mathrm{f}}\right) \\
\text { Frame yield } \\
\text { displacement }\end{array}$ & $\begin{array}{c}\operatorname{Err}\left(\delta_{\mathrm{u}, \mathrm{f}}\right) \\
\begin{array}{c}\text { Frame ultimate } \\
\text { displacement }\end{array}\end{array}$ & $\begin{array}{c}\operatorname{Err}\left(\delta_{\mathrm{y}, \mathrm{w}}\right) \\
\text { Wall yield } \\
\text { displacement }\end{array}$ & $\begin{array}{c}\operatorname{Err}\left(\delta_{\mathrm{u}, \mathrm{w}}\right) \\
\text { Wall ultimate } \\
\text { displacement }\end{array}$ & $\begin{array}{c}\operatorname{Err}\left(\mathrm{V}_{\mathrm{b}, \mathrm{ULS}}\right) \\
\text { Total ultimate } \\
\text { base shear }\end{array}$ & $\begin{array}{c}\operatorname{Err}\left(\mathrm{H}_{\mathrm{CF}}\right) \\
\text { contra-flexure } \\
\text { height @ULS }\end{array}$ \\
\hline 25. coupled walls & n.a. & n.a. & 55.2 & 0.6 & 0.0 & 0.4 \\
26. wall frame wall & -22.9 & -3.6 & -2.0 & -5.4 & 3.3 & 0.2 \\
27. no link beams & -50.6 & 27.4 & -0.8 & 39.4 & -0.2 & -0.6 \\
28. asymmetric & -31.2 & 11.3 & -1.4 & -6.4 & 0.8 & 0.2 \\
\hline Average & $\mathbf{3 4 . 9}$ & $\mathbf{1 4 . 1}$ & $\mathbf{1 4 . 9}$ & $\mathbf{1 3 . 0}$ & $\mathbf{1 . 1}$ & $\mathbf{0 . 3}$ \\
\hline
\end{tabular}

\subsection{Accuracy of the procedure}

The capacity curves for the entire database are summarised in Figure 13 and Table 4, where they are defined by means of the base shear and displacement at the significant limit states, i.e. yielding and ultimate. The error trends reported in Table 1, Table 2 and Table 3 are condensed and summarised in Figure 14 by means of SLaMA-to-numerical ratios of the selected parameters.
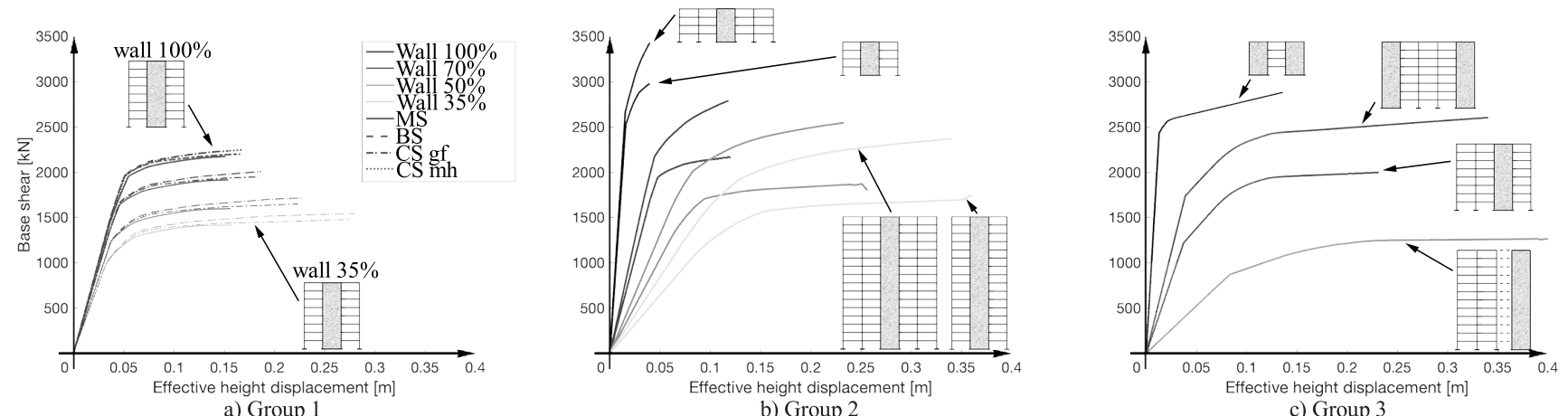

Figure 13. Numerical pushover curves for the entire database divided by Groups 1, 2, 3.

The results show that for the 28 analysed case studies, the proposed SLaMA procedure is particularly reliable in predicting the capacity curve and the plastic mechanism of RC dual wall/frame systems. Moreover, the error trends are well-contained and rather insensitive to changes in geometrical configurations, dimensions of the structure, wall-frame strength proportions and hierarchy of strength of the frame part. 
For all the considered case studies, the total ultimate base shear is slightly over-predicted $(4.3 \%$, on average), except for one case study for which slight under-prediction is observed. The ultimate displacement of the wall, which caused the ULS of the structure in the totality of the cases, is slightly overpredicted for the majority of the case studies (5.7\%, on average), while the over-prediction is equal to $15.5 \%$ for yielding (on average). The greatest error is found in the frame yielding and ultimate displacement (34.4\% and $12.1 \%$ average over-prediction, respectively). However, in no case this influenced the procedure since the wall part always governed the ULS. Finally, the contra-flexure height prediction matched the numerical results with extreme accuracy (2.2\% average over-prediction). 
Table 4. Significant points of the pushover curves for the entire database. (SLaMA results are provided in brackets).

\begin{tabular}{|c|c|c|c|c|c|c|c|c|c|c|c|c|c|}
\hline \multicolumn{2}{|c|}{ Case study } & \multicolumn{2}{|c|}{$\Delta \mathrm{y}, \mathrm{w}[\mathrm{cm}]$} & \multicolumn{2}{|c|}{$\Delta \mathrm{y}, \mathrm{f}[\mathrm{cm}]$} & \multicolumn{2}{|c|}{$\Delta \mathrm{u}[\mathrm{cm}]$} & \multicolumn{2}{|c|}{$\mathrm{V}_{\mathrm{By}, \mathrm{w}}[\mathrm{kN}]$} & \multicolumn{2}{|c|}{$\mathrm{V}_{\mathrm{By}, \mathrm{f}}[\mathrm{kN}]$} & \multicolumn{2}{|c|}{$\mathrm{V}_{\mathrm{Bu}}[\mathrm{kN}]$} \\
\hline \multirow[t]{16}{*}{ G1 } & 1. Mixed-Sway wall $100 \%$ & 5.4 & (6.0) & n.a. & $(8.6)$ & 15.1 & (17.3) & 1937.0 & (2204.5) & n.a. & $(2342.5)$ & 2172.0 & $(2342.5)$ \\
\hline & 2. Mixed-Sway wall 75\% & 4.6 & (5.5) & 14.2 & (8.5) & 15.4 & (17.7) & 1643.0 & (1911.4) & 1910.0 & (2077.4) & 1913.0 & (2077.4) \\
\hline & 3. Mixed-Sway wall 50\% & 3.7 & (4.6) & 13.5 & (8.4) & 15.7 & (17.5) & 1239.0 & (1541.4) & 1590.0 & (1758.4) & 1596.0 & (1758.4) \\
\hline & 4. Mixed-Sway wall 35\% & 3.3 & (3.9) & 13.1 & (8.4) & 15.8 & (17.4) & 999.8 & (1337.0) & 1410.0 & (1590.3) & 1414.0 & (1590.3) \\
\hline & 5. Beam-Sway wall $100 \%$ & 5.2 & (6.1) & n.a. & $(16.0)$ & 15.4 & (17.3) & 1974.0 & (1994.7) & n.a. & (2399.8) & 2226.0 & (2399.8) \\
\hline & 6. Beam-Sway wall 75\% & 4.6 & (5.5) & n.a. & (15.9) & 18.7 & (19.0) & 1664.0 & (1709.0) & n.a. & $(2134.7)$ & 2006.0 & (2134.7) \\
\hline & 7. Beam-Sway wall 50\% & 3.8 & (4.6) & 19.8 & (15.8) & 22.7 & (22.8) & 1249.0 & (1353.4) & 1700.0 & $(1815.7)$ & 1714.0 & (1815.7) \\
\hline & 8. Beam-Sway wall 35\% & 3.3 & (4.0) & 19.7 & $(15.7)$ & 28.0 & (27.9) & 1012.0 & (1158.9) & 1515.1 & $(1647.6)$ & 1543.0 & (1647.6) \\
\hline & 9. Col-Sway (mh) wall $100 \%$ & 6.1 & (6.0) & 15.3 & (10.3) & 16.6 & (17.3) & 2028.0 & $(2215.4)$ & 2192.1 & $(2327.4)$ & 2197.0 & $(2327.4)$ \\
\hline & 10. Col-Sway (mh) wall $75 \%$ & 4.5 & (5.5) & 15.2 & $(10.2)$ & 18.4 & $(19.0)$ & 1648.0 & (1937.0) & 1934.0 & $(2062.4)$ & 1947.0 & (2062.4) \\
\hline & 11. Col-Sway (mh) wall $50 \%$ & 3.7 & (4.5) & 14.3 & $(10.2)$ & 22.3 & $(22.7)$ & 1242.0 & (1593.5) & 1610.1 & $(1743.4)$ & 1648.0 & $(1743.4)$ \\
\hline & 12. Col-Sway (mh) wall $35 \%$ & 3.2 & (3.9) & 13.8 & $(10.1)$ & 27.5 & $(27.8)$ & 992.0 & (1407.6) & 1428.0 & $(1575.2)$ & 1477.0 & $(1575.2)$ \\
\hline & 13. Col-Sway (gf) wall $100 \%$ & 5.2 & (6.1) & n.a. & (16.0) & 16.8 & $(17.3)$ & 1953.0 & (1992.3) & n.a. & $(2397.5)$ & 2245.0 & $(2397.5)$ \\
\hline & 14. Col-Sway (gf) wall $75 \%$ & 4.6 & (5.5) & n.a. & (15.9) & 18.7 & $(19.0)$ & 1644.7 & $(1706.6)$ & n.a. & $(2132.4)$ & 2005.0 & (2132.4) \\
\hline & 15. Col-Sway (gf) wall 50\% & 3.8 & (4.6) & 19.9 & $(15.8)$ & 22.7 & $(22.8)$ & 1233.0 & (1350.9) & 1700.0 & $(1813.3)$ & 1713.0 & (1813.3) \\
\hline & 16. Col-Sway (gf) wall $35 \%$ & 3.3 & $(4.0)$ & 19.6 & (15.7) & 28.0 & (27.9) & 988.1 & $(1156.5)$ & 1513.9 & $(1645.2)$ & 1542.0 & $(1645.2)$ \\
\hline \multirow[t]{8}{*}{ G2 } & 17. 4-storey 2-bays & 1.6 & (1.7) & n.a. & (4.1) & 4.0 & $(5.2)$ & 2519.9 & $(2840.6)$ & n.a. & $(3120.6)$ & 2975.0 & (3120.6) \\
\hline & 18. 8-storey 2-bays & 4.8 & (5.5) & n.a. & (8.3) & 12.0 & (13.0) & 1941.0 & (2141.6) & n.a. & (2313.3) & 2157.0 & (2313.3) \\
\hline & 19. 12-storey 2-bays & 9.4 & $(11.0)$ & 24.5 & (12.7) & 25.7 & $(23.8)$ & 1706.0 & (1934.1) & 1857.1 & $(2008.5)$ & 1798.0 & $(2008.5)$ \\
\hline & 20. 16-storey 2-bays & 15.6 & $(17.8)$ & n.a. & (18.0) & 36.0 & (37.3) & 1572.9 & (1837.9) & n.a. & (1849.3) & 1749.0 & (1849.3) \\
\hline & 21. 4-storey 4-bays & 1.5 & $(1.7)$ & n.a. & $(4.0)$ & 4.0 & $(5.2)$ & 2666.5 & (3149.9) & n.a. & (3789.2) & 3426.0 & (3789.2) \\
\hline & 22. 8-storey 4-bays & 4.4 & (4.9) & n.a. & (8.1) & 11.8 & (12.5) & 2152.3 & (2530.3) & n.a. & (2989.3) & 2786.0 & (2989.3) \\
\hline & 23. 12-storey 4-bays & 8.2 & (9.4) & n.a. & (12.4) & 23.3 & $(22.6)$ & 1999.4 & (2394.0) & n.a. & (2689.3) & 2543.0 & (2689.3) \\
\hline & 24. 16-storey 4-bays & 13.0 & (15.0) & n.a. & (17.1) & 34.1 & (35.4) & 1926.8 & (2377.9) & n.a. & $(2529.3)$ & 2366.0 & (2529.3) \\
\hline \multirow[t]{4}{*}{ G3 } & 25. coupled walls & 1.1 & (1.6) & n.a. & $(4.0)$ & 13.5 & (13.6) & 2497.0 & (2558.2) & n.a. & (2620.6) & 2867.0 & (2869.3) \\
\hline & 26. wall frame wall & 4.2 & (4.1) & 10.8 & (8.4) & 34.8 & (32.9) & 1953.0 & (2145.7) & 2419.0 & (2504.1) & 2595.0 & (2679.5) \\
\hline & 27. no link beams & 11.2 & (9.8) & 23.5 & (11.7) & 38.6 & (38.6) & 1107.0 & (1092.7) & 1247.8 & (1226.3) & 1237.0 & (1234.0) \\
\hline & 28. asymmetric & 4.0 & (3.9) & 11.0 & (7.8) & 30.5 & (28.6) & 1463.0 & (1574.6) & 1944.8 & (1988.2) & 2034.0 & (2049.3) \\
\hline
\end{tabular}



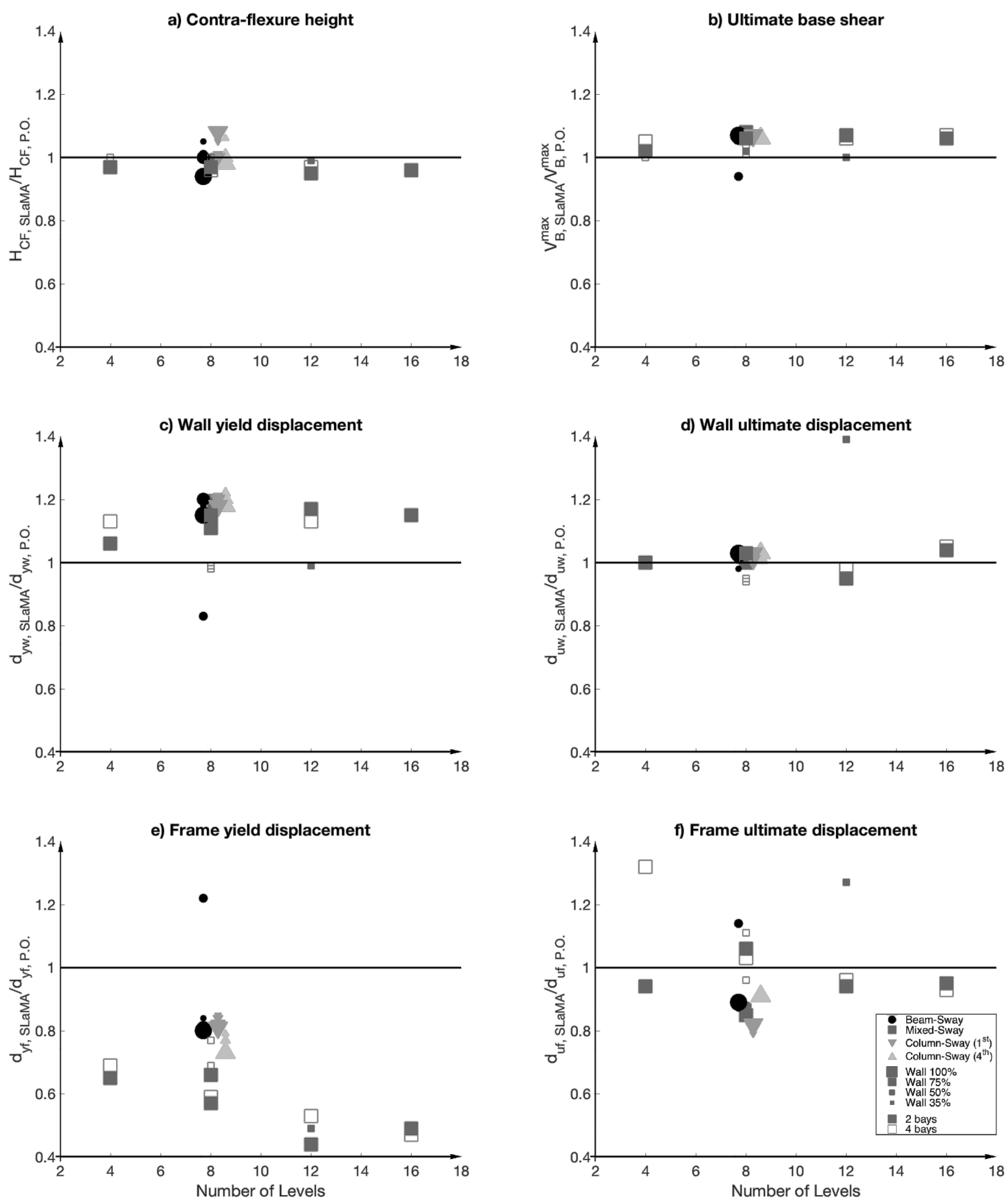

Figure 14 SLaMA-to-numerical ratios for selected parameters.

\section{Conclusions}

This paper deals with the analytical evaluation of the non-linear capacity curve of RC dual wall/frame systems. A novel "by hand" procedure -thus implementable in a spreadsheet- is proposed in the framework of the Simple Lateral Mechanism Analysis (SLaMA) method [NZSEE 2017]. A parametric analysis is 
conducted for 28 case studies dual systems with different geometrical configurations (number and position of the wall(s), presence of link beams), dimensions (2:4 bays, 4:16 storeys), wall-frame strength proportions and hierarchy of strength of the frame part. The proposed SLaMA procedure is validated through the comparison with refined numerical pushover analyses. It is worth mentioning that this work is based on a rigid diaphragm hypothesis, which can be inappropriate for some existing $\mathrm{RC}$ structure. The effects of diaphragm strength, stiffness and deformation capacity will be investigated in future research.

The key findings of this paper can be summarised as follows:

- A novel SLaMA procedure for the assessment of dual wall/frame systems is proposed. In the calculation of the capacity curve, the transfer forces between the frame and wall part are explicitly considered. Moreover, it is also possible to consider the concentrated moment couples due to link beams (if any) connecting the frame and the wall(s);

- A parametric SLaMA vs numerical pushover validation of the method, based on 28 ideal case studies, demonstrates the very satisfactory performance of the proposed procedure. The results clearly indicate that the dual system behaviour is captured with negligible discrepancy with respect to the numerical analyses;

- The total base shear at the ULS is matching the numerical results, with an average over-prediction equal to $4.3 \%$;

- The wall ultimate displacement, which caused the ULS of the structure for all the case studies, is generally slightly over-predicted with absolute mean error equal to $5.7 \%$, while the error is equal to $15.5 \%$ for the yielding displacement;

- The greatest error is observed for the frame yielding and ultimate displacement $(34.4 \%$ and $12.1 \%$ on average, respectively). However, in no case this influenced the capacity curve as the ULS is governed by the wall capacity;

- The prediction of contra-flexure height matches the numerical results with $2.2 \%$ average error. 
The results of this work indicate that the proposed procedure is able to capture the non-linear behaviour of RC dual wall/frame systems with particular accuracy with respect to numerical pushover results. For this reason, this procedure is deemed to be a valid alternative to a numerical analysis.

\section{Acknowledgements}

This study was performed in the framework of the "SAFER Concrete Technology" and "Advancements in Engineering Guidelines and Standards" projects, funded by the New Zealand Natural Hazard Research Platform (NHRP) and of the PE 2014-2018 joint program DPC (Italian Department of Civil Protection) ReLUIS (Laboratories University Network of Seismic Engineering).

\section{References}

1. Baltzopoulos, G., Baraschino, R., Iervolino, I. and Vamvatsikos, D. (2017). SPO2FRAG: software for seismic fragility assessment based on static pushover. Bulletin of Earthquake Engineering, 15: 4399-4425.

2. Berry, M.P. \& Eberhard, M.O., 2005. Practical Performance Model for Bar Buckling. Journal of Structural Engineering, 131, pp.1060-1070.

3. Borzi, B., Pinho, R. \& Crowley, H., 2008. Simplified pushover-based vulnerability analysis for large-scale assessment of RC buildings. Engineering Structures, 30, pp.804-820.

4. Calvi, G. \& Sullivan, T., 2013. Developing guidelines for displacement-based seismic assessment. The state of Earthquake Engineering Research in Italy: the ReLUIS-DPC 2010-2013 Project, pp.327-352.

5. Calvi, G.M., Magenes, G. \& Pampanin, S., 2002. Relevance of beam-column joint damage and collapse in RC frame assessment. Journal of Earthquake Engineering, 6(1), pp.75-100.

6. Cardone D., Flora A., 2017 Multiple inelastic mechanisms analysis (MIMA): A simplified method for the estimation of the seismic response of RC frame buildings. Engineering Structures, 145(15), pp. 368-380.

7. Carr, A.J., 2016. RUAUMOKO2D - The Maori God of Volcanoes and Earthquakes. Inelastic Analysis Finite Element program. Christchurch, New Zealand.

8. Crowley, H., Pinho, R. \& Bommer, J., 2004. A Probabilistic Displacement-based Vulnerability Assessment Procedure for Earthquake Loss Estimation. Bulletin of Earthquake Engineering, 2(2), pp. 173-219.

9. Del Vecchio, C., Gentile, R. \& Pampanin, S., 2017. The Simple Lateral Mechanism Analysis (SLaMA) for the seismic performance assessment of a case study building damaged in the 2011 Christchurch earthquake, Research report N. 2016-02, University of Canterbury, Christchurch, New Zealand.

10. Del Vecchio, C., Gentile, R., Di Ludovico, M., Uva, G., Pampanin, S., 2018. Implementation and validation of the Simple Lateral Mechanism Analysis (SLaMA) for the seismic performance assessment of a damaged case study building. Journal of Earthquake Engineering, accepted for publication, doi: 10.1080/13632469.2018.1483278.

11. European Committee for Standardisation, 2005. Eurocode 8: Design of structures for earthquake resistance. Part 3: Strengthening and repair of buildings. 
12. Fajfar, P. \& Fischinger, M. (1988), 'N2 - A method for non-linear seismic analysis of regular buildings', 9th world conference on earthquake engineering. Tokyo, Japan.

13. Gentile, R., 2017. Extension, refinement and validation of the Simple Lateral Mechanism Analysis (SLaMA) for the seismic assessment of RC structures. PhD thesis, Department of Civil, Environmental and Landscape, Building Engineering and Chemistry, Polytechnic University of Bari, Bari, Italy.

14. Gentile, R., Porco, F., Raffaele, D., \& Uva, G., 2018a. Simplified Moment-Curvature relationship in analytical form for RC circular sections. Bulletin of the New Zealand Society for Earthquake Engineering, 51(3), 145-158.

15. Gentile, R., \& Raffaele, D., 2018b. Simplified analytical Moment-Curvature relationship for hollow circular RC cross-sections. Earthquakes and Structures, 15(4), 419-429.

16. Gentile, R., Del Vecchio, C., Pampanin, S., Raffaele, D., Uva, G., 2019a. Refinement and validation of the Simple Lateral Mechanism Analysis (SLaMA) procedure for RC frames. Journal of Earthquake Engineering, in press, doi: 10.1080/13632469.2018.1560377.

17. Gentile, R., Raffaele, D., Uva, G., Pampanin, S., 2019b. Non-linear analysis of RC masonryinfilled frames using the SLaMA method. Part 1: mechanical interpretation of the infill/frame interaction and formulation of the procedure. Bulletin of Earthquake Engineering, accepted for publication.

18. Gentile, R., Raffaele, D., Uva, G., Pampanin, S., 2019c. Non-linear analysis of RC masonryinfilled frames using the SLaMA method. Part 2: parametric analysis and validation of the procedure. Bulletin of Earthquake Engineering, submitted.

19. Glaister, S. \& Pinho, R., 2003. Development of a simplified deformation-based method for seismic vulnerability assessment. Journal of Earthquake Engineering, 7(1), pp.107-140.

20. King, D.J., Priestley, M.J.N. \& Park, R., 1986. Computer programs for concrete column design, Research Report 86/12, Department of Civil Engineering.

21. Kowalsky, M.J. \& Priestley, M.J.N., 2000. Improved analytical model for shear strength of circular reinforced concrete columns in seismic regions. ACI Structural Journal, 97, pp.388-396.

22. Krolicki, J., Maffei, J. \& Calvi, G.M., 2011. Shear Strength of Reinforced Concrete Walls Subjected to Cyclic Loading. Journal of Earthquake Engineering, 15, pp.30-71.

23. Lopes, M.S. \& Bento, R., 2001. Seismic behavior of dual systems with column hinging. Earthquake Spectra, 17(4), pp.657-677.

24. Magenes, G. \& Pampanin, S., 2004. Seismic response of gravity-load design frames with masonry infills. In 13th World Conference on Earthquake Engineering.

25. Mander, J.B., Priestley, M.J.N. \& Park, R., 1988. Theoretical stress strain model for confined concrete. Journal of Structural Engineering, 114(8), pp.1804-1826.

26. Montejo, L.A. \& Kowalsky, M.J., 2007. Set of codes for the analysis of reinforced concrete members, Raleigh, North Carolina.

27. NZSEE, 2006. New Zealand Society for Earthquake Engineering, Assessment and improvement of the structural performance of buildings in earthquakes. Wellington, New Zealand.

28. NZSEE, 2017. New Zealand Society for Earthquake Engineering, The seismic assessment of existing buildings - technical guidelines for engineering assessments. Wellington, New Zealand.

29. Pampanin, S., Calvi, G.M. \& Moratti, M., 2002. Seismic behaviour of R.C. Beam-column joints designed for gravity loads. In 12th European Conference on Earthquake Engineering.

30. Pampanin, S., Magenes, G. \& A. Carr. 2003. Modelling of Shear Hinge Mechanism in Poorly Detailed RC Beam-Column Joints. fib Symposium 2003: "Concrete Structures in Seismic Regions", May 2003. pp. 126-137.

31. Pampanin, S., Bologini, D., \& Pavese, A., 2007. Performance-Based Seismic Retrofit Strategy for Existing Reinforced Concrete Frame Systems Using Fiber-Reinforced Polymer Composites. Journal of Composites for Construction, 11(2), pp.211-226. 
32. Paulay, T. and Goodsir, W., I986. The capacity design of reinforced concrete hybrid structures for multistorey buildings. Bulletin of NZ National Society for Earthquake Engineering, New Zealand 19(1), 1-17.

33. Paulay, T., 2001. Some design principles relevant to torsional phenomena in ductile buildings. Journal of Earthquake Engineering, 5(3), pp.273-308.

34. Priestley, M. \& Calvi, G., 1991. Towards a capacity-design assessment procedure for reinforced concrete frames. Earthquake Spectra, 7(3), pp.413-437.

35. Priestley, M., Seible, F. \& Calvi, G.M., 1996. Seismic design and retrofit of bridges, New York, USA: John Wiley and Sons.

36. Priestley, M., 1997. Displacement-based seismic assessment of reinforced concrete buildings. Journal of Earthquake Engineering, 1(1), pp.157-192.

37. Priestley, M.J.N., Calvi, G.M. \& Kowalsky, M.J., 2007. Displacement-based seismic design of structures, IUSS Press, Pavia, Italy.

38. Quintana Gallo, P., 2014. The nonlinear dynamics involved in the seismic assessment and retrofit of reinforcement concrete buildings. $\mathrm{PhD}$ thesis, Department of Civil and Natural Resource Engineering, University of Canterbury.

39. Rossetto, T., Gehl, P., Minas, S., Galasso, C., Duffour P., Douglas J., Cook, O. (2016). FRACAS: A capacity spectrum approach for seismic fragility assessment including record-to-record variability. Engineering Structures, 125: 337-348.

40. Rutenberg, A. and Nsieri, E. (2006). The seismic shear demand in ductile cantilever all systems and the EC8 provisions. Bulletin of Earthquake Engineering, 4, pp. 1-21.

41. Sharpe, R.D., 1976. The Seismic Response of Inelastic Structures. PhD thesis, Department of Civil Engineering, University of Canterbury, Christchurch, New Zealand.

42. Simonini, S. et al., 2012. Pushover analysis of multi-storey cantilever wall systems. In 15th World Conference on Earthquake Engineering. Lisbona, Portugal.

43. Sullivan, T.J., Priestley, M. \& Calvi, G.M., 2006. Direct displacement-based design of frame-wall structures. Journal of Earthquake Engineering, 10(1), pp.91-124.

44. Sullivan, T. \& Calvi, G.M., 2011. Considerations for the Seismic Assessment of Buildings Using the Direct Displacement-Based Assessment Approach. In Associazione nazionale di ingegneria sismica in Italia (ANIDIS).

45. Sullivan, T.J., Welch, D.P. \& Calvi, G.M., 2014. Simplified seismic performance assessment and implications for seismic design. Earthquake engineering and engineering vibrations, 13, pp.95122.

46. Sullivan, T.J. \& Fox, M.J., 2015. Development of a simplified displacement-based procedure for the seismic assessment of RC wall buildings. In 5th ECCOMAS Thematic Conference on Computational Methods in Structural Dynamics and Earthquake Engineering.

47. Welch, D.P., Sullivan, T.J. \& Calvi, G.M., 2014. Developing Direct Displacement-Based Procedures for Simplified Loss Assessment in Performance-Based Earthquake Engineering. Journal of Earthquake Engineering, 18(September 2013), pp.290-322. 